\title{
BENTUK-BENTUK GEOMETRIS PADA POLA KERAJINAN ANYAMAN SEBAGAI KEARIFAN LOKAL DI KABUPATEN BARITO KUALA
}

\author{
Muhammad Royani, Winda Agustina \\ Pendidikan Matematika STKIP PGRI Banjarmasin \\ hmroyani@stkipbjm.ac.id, winda.agustina@stkipbjm.ac.id
}

\begin{abstract}
Abstrak: Indonesia memiliki ragam budaya yang khas. Di antara wujud kebudayaan tersebut adalah adanya hasil fisik berupa aktivitas perbuatan dan semua karya manusia dalam masyarakat. Kabupaten Barito Kuala memiliki wujud kebudayaan yang khas, yaitu kerajinan anyaman. Masyarakat setempat memanfaatkan tanaman purun untuk dijadikan bahan pembuatan kerajinan anyaman dengan pertimbangan bahwa purun adalah tanaman yang mudah ditemukan di rawa karena tumbuh liar dan tekstur seratnya yang kuat. Dibutuhkan keterampilan untuk menghasilkan anyaman yang memiliki nilai nilai estetika dan nilai ekonomis tinggi. Metode penelitian yang digunakan adalah metode kualitatif deskriptif. Data bersumber dari pengrajin anyaman purun di Kabupaten Barito Kuala. Teknik analisis data yang digunakan adalah analisis data kualitatif model Miles, yaitu interaktif dan berlangsung terus menerus sampai tuntas sehingga data menjadi jenuh. Hasil penelitian menunjukkan beberapa motif anyaman purun memiliki bentuk geometri bangun datar, yaitu mata punai dan tapak catur berbentuk persegi, motif saluang mudik berbentuk jajargenjang, motif ramak cangkih berbentuk persegi panjang, motif gigi haruan berbentuk segitiga, dan motif anyam badiri dan anyam barabah menggambarkan susunan garis-garis sejajar. Selain itu, anyaman purun memiliki nilai estetika yang berdampak pada munculnya nilai ekonomi sejalan dengan tingginya kebutuhan masyarakat akan barang-barang yang dihasilkan dari anyaman purun.
\end{abstract}

Kata Kunci: bentuk geometri, anyaman, purun, kearifan lokal

Indonesia adalah negara memiliki ragam budaya yang sangat khas. Budaya yang dibentuk oleh masyarakat berkaitan dengan nilai-nilai sosial yang dipegang oleh masyarakat itu sendiri. Di antara nilainilai tersebut antara lain nilai estetika, nilai moral, dan nilai religius. Manusia sebagai makhluk budaya menggunakan akal dan budinya untuk memenuhi kebutuhan hidupnya. Dengan akal dan budi tersebut manusia mampu menciptakan sesuatu, mempunyai keinginan atau kemauan untuk melakukan sesuatu dengan penuh rasa (keindahan). Salah satu wujud kebudayaan adalah adanya hasil fisik berupa aktivitas perbuatan dan semua karya manusia dalam masyarakat, seperti benda-benda atau hal- hal yang dapat diraba, dilihat, dan difoto (Suratman, 2013: 38).

Kebudayaan berasal dari kata budaya, dalam bahasa Sanskerta yaitu buddhayah yang merupakan bentuk jamak dari buddhi (budi atau akal). Buddhi berarti hal-hal yang berkaitan dengan budi dan akal manusia. Menurut Koentjoroningrat (1981), budaya adalah keseluruhan gagasan dan karya manusia yang harus dibiasakan dengan belajar serta keseluruhan dari hasil budi pekerti. Menurut Taylor (1989), budaya adalah keyakinan dan perilaku yang diaturkan atau diajarkan manusia kepada generasi berikutnya. Definisi budaya juga diungkapkan oleh Harris (1999), yaitu seluruh aspek kehidupan manusia dalam 
masyarakat yang diperoleh dengan cara belajar, termasuk pikiran dan tingkah laku. Jadi, dapat disimpulkan budaya adalah seluruh gagasan maupun karya manusia yang menjadi kebiasaan masyarakat setempat dan diajarkan kepada generasi berikutnya.

Menurut pandangan antropologi tradisional budaya terbagi dua bagian, yaitu budaya material dan budaya non material. Budaya material berupa objek seperti pakaian, seni, makanan, dan bendabenda kepercayaan. Sedangkan budaya non material mencakup kepercayaan, pengetahuan, nilai, norma, dan sebagainya. Menurut Koentjaraningrat (1974) wujud kebudayaan ada tiga macam, yaitu (1) kebudayaan sebagai kompleks ide, gagasan, nilai, norma, dan peraturan, (2) kebudayaan sebagai suatu kompleks aktivitas kelakuan berpola manusia dalam masyarakat, dan (3) benda-benda sebagai karya manusia.

Selanjutnya budaya yang menjadi kebiasaan suatu kelompok atau masyarakat disebut kearifan lokal. Menurut Rahyono (2009), kearifan lokal merupakan kecerdasan manusia yang dimiliki oleh kelompok etnis tertentu yang diperoleh melalui pengalaman masyarakat. Artinya, pengalaman yang dimiliki oleh suatu masyarakat belum tentu dialami oleh masyarakat lain. Hayati Soebadio berpendapat bahwa kearifan lokal merupakan suatu identitas/kepribadian budaya bangsa yang menyebabkan bangsa tersebut mampu menyerap dan mengolah kebudayaan asing sesuai watak dan kemampuan sendiri (Ayatrohaedi, 1986). Selanjutnya, kearifan lokal mempunyai ciri-ciri yaitu:

a. mampu bertahan terhadap budaya luar, b. memiliki kemampuan mengakomodasi unsur-unsur budaya luar,

c. mempunyai kemampuan mengintegrasikan unsur budaya luar ke dalam budaya asli,

d. mempunyai kemampuan mengendalikan, dan

e. mampu memberi arah pada perkembangan budaya.

Di antara wujud kebudayaan masyarakat yang dimiliki Kabupaten Barito Kuala, salah satunya adalah kerajinan anyaman. Menganyam berarti mengatur bilah atau lembaran-lembaran secara tindih-menindih dan silangmenyilang (Dina dkk, 2015). Kerajinan anyaman dibuat dengan memanfaatkan bahan alami. Bahan anyaman yang sering digunakan adalah purun, yaitu tumbuhan liar sejenis rumput yang tumbuh di dekat air atau rawa. Purun mempunyai serat yang cukup kuat sehingga masyarakat Kabupaten Barito Kuala menjadikannya sebagai salah satu bahan kerajinan tangan yaitu anyaman. Pemilihan bahan untuk kerajinan anyaman perlu memperhatikan fungsi dan keindahan benda yang akan dibuat. Dua jenis purun yang biasa dimanfaatkan untuk membuat anyaman adalah purun danau dan purun tikus.

Cara pembuatannya adalah purun yang cukup tinggi dipotong dan dikumpulkan. Batang purun perlu dibersihkan terlebih dahulu dengan cara menggosok-gosokkan dengan abu dapur untuk menghilangkan lapisan kandungan silica dari kulit purun dan dicuci bersih. Kemudian purun dijemur di bawah sinar matahari sampai menjadi kering. Setelah proses penjemuran, purun diikat kemudian dipipihkan dengan cara ditumbuk berulang kali dengan kayu ulin hingga batang 
menjadi pipih. Agar lebih menarik, purun dipisah-pisahkan untuk diberi pewarna. Pada umumnya, warna yang digunakan para pengrajin purun adalah warna alami, merah, hijau, ungu, dan biru. Berbagai jenis produk yang dihasilkan antara lain tas, tikar, bakul, topi, kipas, dompet, dan barang-barang lainnya. Dibutuhkan keahlian untuk proses menganyam, pengrajin harus terampil membuat pola agar anyaman bernilai keindahan. Anyaman yang dihasilkan beraneka ragam, seperti keranjang (kampil), topi, tikar, tas, bakul, dan kipas. Anyaman menjadi kearifan lokal masyarakat Kabupaten Barito Kuala. Kearifan lokal mempunyai ciri mampu bertahan terhadap budaya luar. Hingga saat ini, kerajinan anyaman masih tetap digunakan dalam kehidupan sehari-hari masyarakat di Kalimantan Selatan.

Anyaman purun mempunyai berbagai macam motif menarik yang menyerupai bentuk-bentuk geometri. Hubungan bentuk-bentuk geometri yang ada pada budaya sebagai suatu kearifan lokal merupakan salah satu etnomatematika. Istilah etnomatematika muncul pertama kali pada akhir tahun 1960-an, digunakan oleh seorang pendidik dan matematikawan Brazil yaitu Ubiratan D'Ambrosio. Menurut Ambrosio (1977) etnomatematika terdiri dari kombinasi kata ethno (budaya yang dibentuk oleh masyarakat), mathema (penjelasan, pemahaman, lingkungan akan budaya), dan tics (mode, gaya, teknik). Etnomatematika mencakup semua yang dapat diidentifikasi secara budaya seperti jargon, kode, simbol, mitos, bahkan termasuk cara penalaran tertentu dari suatu kelompok.
Menurut Glorin (1980) dan Ascher (1991), etnomatematika merupakan studi tentang praktek matematika pada kelompok budaya tertentu di dalam proses menangani masalah lingkungan dan kegiatan. Kata depan "ethno" mengacu pada kelompok budaya, seperti masyarakat suku nasional, kelas profesional, dan sebagainya. Termasuk juga bahasa dan praktek kehidupan sehari-hari mereka. Jadi, dapat disimpulkan bahwa etnomatematika adalah integrasi matematika dan budaya dengan kearifan lokal kelompok setempat melalui suatu aktivitas.

Selain bernilai estetika, hasil kerajinan anyaman purun tentunya juga bernilai ekonomis dan menjadi peluang usaha yang cukup besar. Nilai adalah ukuran derajat tinggi-rendahnya atau kadar yang dapat diperhatikan, diteliti atau dihayati dalam berbagai obyek yang bersifat fisik (kongkrit) maupun abstrak (Kartika dan Perwira 2004: 20). Nilai-nilai sosial adalah nilai yang dianut oleh suatu masyarakat mengenai apa yang dianggap baik dan buruk.

Robert W. Richey sebagaimana dikutip oleh T. Sulistyono (1991: 15) membagi nilai menjadi tujuh macam, yaitu (1) nilai intelektual, (2) nilai personal dan fisik, (3) nilai kerja, (4) nilai penyesuaian, (5) nilai sosial, (6) nilai keindahan, dan (7) nilai rekreasi. Adapun menurut Notonegoro, nilai dibagi menjadi tiga macam, yaitu:

\section{a. Nilai material}

Nilai material adalah segala sesuatu yang berguna bagi jasmani/unsur fisik manusia. Sebagai contoh, batu gunung. Secara materi batu gunung mempunyai nilai tertentu. Hal ini disebabkan batu gunung dapat digunakan untuk 
membangun sebuah rumah tinggal. Nilai yang yang terkandung dalam batu gunung ini dinamakan nilai material.

\section{b. Nilai vital}

Nilai vital adalah segala sesuatu yang berguna bagi manusia untuk melakukan suatu kegiatan dan aktivitas. Contoh jas hujan, mempunyai kegunaan untuk menaungi tubuh dari air hujan. Apabila jas hujan ini robek maka nilai kegunaan jas hujan menjadi berkurang. Nilai jas hujan oleh karena kegunaannya dinamakan nilai vital.

\section{c. Nilai kerohanian}

Nilai kerohanian adalah segala sesuatu yang berguna bagi batin (rohani) manusia. Nilai kerohanian manusia dibedakan menjadi empat macam, yaitu:

1) nilai kebenaran adalah nilai yang bersumber pada unsur akal manusia,

2) nilai keindahan adalah nilai yang bersumber pada perasaan manusia (nilai estetika),

3) nilai moral (kebaikan) adalah nilai yang bersumber pada unsur kehendak atau kemauan (karsa dan etika), dan

4) nilai religius adalah/nilai ketuhanan yang tertinggi, yang sifatnya mutlak dan abadi.

Produk anyaman purun sangat khas dan dapat digunakan dalam waktu yang lama, maka produk anyaman dapat menjadi oleh-oleh khas Kalimantan Selatan khususnya Kabupaten Barito Kuala. Namun di balik itu, perlu ditelusuri lebih lanjut apakah anyaman purun yang dihasilkan mempunyai nilai-nilai tertentu atau tidak.

\section{Metode Penelitian}

Penelitian ini bertujuan untuk mendeskripsikan bentuk-bentuk geometris pada pola kerajinan anyaman dan nilainilai yang terkandung sebagai kearifan lokal di Kabupaten Barito Kuala. Hasil sajian data penelitian berupa deskripsi bentuk-bentuk geometris pada pola kerajinan anyaman sebagai kearifan lokal di Kabupaten Barito Kuala. Berdasarkan tujuan tersebut, maka metode yang digunakan dalam penelitian ini adalah penelitian kualitatif dengan pendekatan. Penelitian kualitatif dipilih untuk memberikan deskripsi naratif dengan penilaian setelah melalui triangulasi data.

Sumber data dalam penelitian ini adalah pengrajin anyaman di Kabupaten Barito Kuala dan fokus penelitian pada bentuk-bentuk geometris, serta menelusuri nilai-nilai yang terkandung pada kerajinan anyaman purun yang dibuat. Kriteria informan yang ditentukan adalah pengrajin sudah menekuni kerajinan anyaman purun minimal 10 tahun. Sumber data beralamat di Jalan Atak Imberansyah RT 06 RW 02, Kelurahan Lepasan, Kecamatan Bakumpai, Kabupaten Barito Kuala.

\section{Hasil dan Pembahasan}

Penelitian ini dilaksanakan pada bulan Maret 2017 di kelurahan Lepasan, kecamatan Bakumpai, kabupaten Barito Kuala. Informasi diperoleh dari empat orang pengrajin anyaman purun, yaitu HM (65 tahun ), BK ( 47 tahun), RA ( 33 tahun), dan TF (30 tahun). Dari aktivitas pengumpulan data diperoleh informasi bahwa ada berbagai macam kerajinan anyaman yang dihasilkan dari tanaman purun danau. Di antaranya anyaman purun dijadikan tas, bakul, tikar, topi, taplak meja, peci, sandal, tempat tisu, dan 
lainnya. Adapun macam-macam motif anyaman yang sering dibuat, di antaranya adalah sebagai berikut.

\section{a. Mata Punai}

Motif mata punai mempunyai ciri khas berbentuk kotak-kotak dan memiliki titik di tengah menyerupai mata. Semakin besar ukuran anyaman mata punai, semakin banyak pula lapisan bentuk di dalamnya. Punai adalah nama burung yang merupakan hewan dilindungi.

b. Tapak Catur

Motif tapak catur mempunyai ciri khas berbentuk susunan kotak dengan kombinasi dua atau tiga warna yang beraturan seperti papan catur. Beberapa permintaan konsumen menginginkan ukuran kotak yang berbeda sehingga menjadi kombinasi bentuk persegi dan persegi panjang.

Motif mata punai dan tapak catur memiliki kesamaan, yaitu secara geometris membentuk bangun datar persegi, dimana ciri-cirinya adalah memiliki empat titik sudut, empat sisi yang sama panjang, dua diagonal sama panjang, empat simetri lipat, dan empat simetri putar. Perbedaannya adalah satu motif mata punai terpisah dengan mata punai lainnya dan pada tapak catur tersusun dalam satu lajur. Anyaman purun dengan motif mata punai dan tapak catur dapat dimanfaatkan sebagai media pembelajaran untuk mempelajari tentang definisi dan sifat-sifat persegi. Selanjutnya motif mata punai dapat pula dimanfaatkan untuk mempelajari definisi, sifat-sifat, keliling, dan luas persegi.

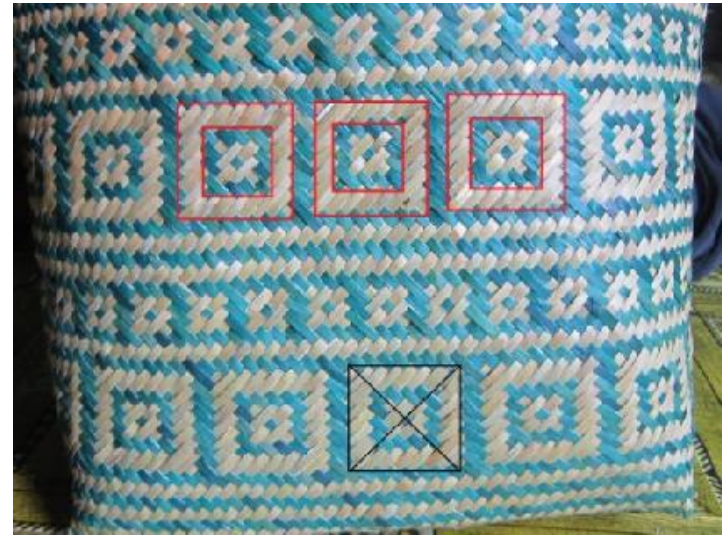

Gambar 1. Bentuk Geometris Mata Punai

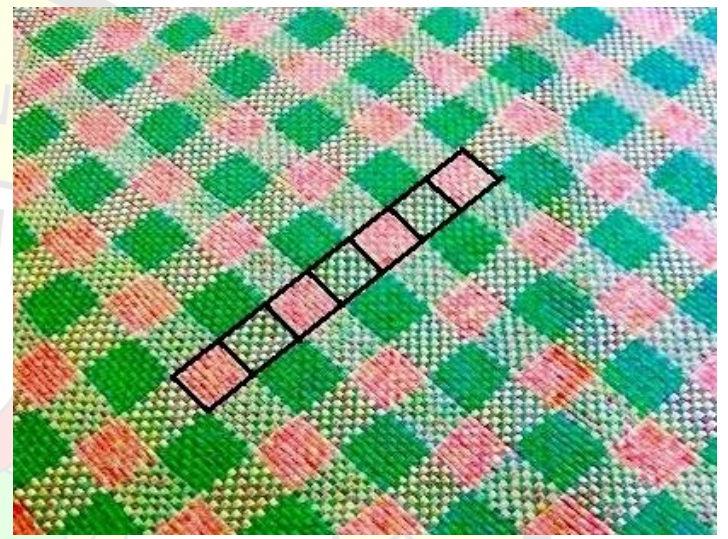

Gambar 2. Bentuk Geometris Tapak Catur

c. Saluang Mudik

Motif saluang mudik mempunyai ciri khas anyaman dengan patahan garisgaris yang searah, dengan ujung-ujung garis pada setiap lajur saling menyambung. Kombinasi warna dapat diterapkan pada setiap garis maupun setiap lajur atau barisnya.

Motif saluang mudik secara geometris membentuk bangun jajargenjang, dimana ciri-cirinya adalah tidak memiliki simetri lipat, mempunyai satu simetri putar, sisi-sisi yang berhadapan sejajar dan sama panjang, dua sisi lainnya tidak saling tegak lurus, sepasang diagonal tidak sama panjang dan tidak tegak lurus, serta jumlah sudut yang saling berdekatan adalah $180^{\circ}$. Motif saluang mudik dapat dimanfaatkan sebagai media pembelajaran untuk mempelajari 
tentang definisi, sifat-sifat, keliling, dan luas jajargenjang.



Gambar 3. Bentuk Geometris Saluang Mudik

d. Ramak Cangkih

Motif ramak cangkih mempunyai ciri khas anyaman-anyaman kecil seperti cengkeh yang disusun vertikal dan horisontal secara bergantian. Baris anyaman dapat dibuat mendatar maupun miring untuk menambah keindahan.

Motif ramak cangkih secara geometris dapat dipandang sebagai susunan persegi panjang dengan mempunyai ciri-ciri serupa yaitu mempunyai dua pasang sisi berhadapan sejajar dan sama panjang, sisi-sisinya saling tegak lurus sehingga membentuk sudut $90^{\circ}$, memiliki dua simetri lipat dan dua simetri putar, serta kedua diagonal sama panjang. Motif ramak cangkih dapat dimanfaatkan sebagai media pembelajaran untuk mempelajari tentang definisi, sifatsifat, keliling, dan luas persegi panjang.

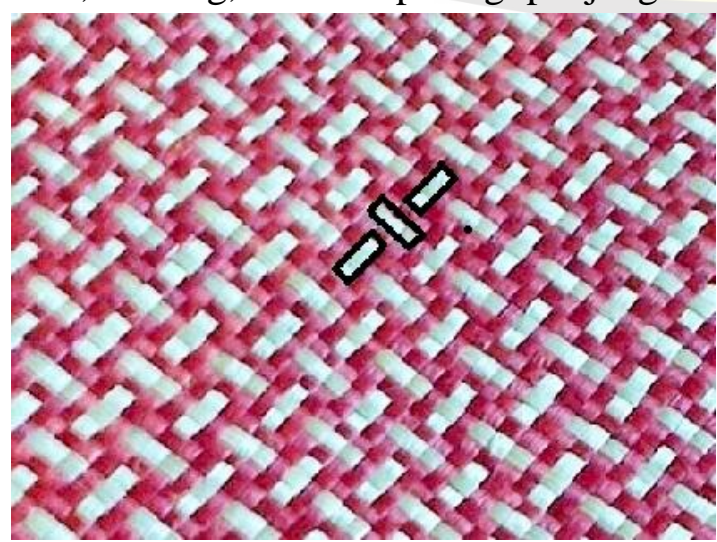

Gambar 4. Bentuk Geometris Ramak Cangkih e. Gigi Haruan

Motif gigi haruan mempunyai ciri khas berbentuk segitiga yang disusun berjejer dalam satu jalur seperti susunan gigi atas dan bawah ikan haruan atau ikan gabus.

Motif gigi haruan secara geometris dapat dipandang sebagai susunan segitiga samakaki maupun samasisi dengan ciri-ciri dibatasi oleh tiga garis lurus (ketiganya sama panjang maupun dua di antaranya sama panjang) sehingga membentuk tiga buah sudut yang jumlahnya $180^{\circ}$. Seluruh segitiga yang disusun adalah kongruen. Motif gigi haruan dapat dimanfaatkan sebagai media pembelajaran untuk mempelajari tentang definisi, sifat-sifat, keliling, dan luas segitiga.



Gambar 5. Bentuk Geometris Gigi Haruan

Keunikan dan keindahan anyaman purun mempunyai nilai estetika. Nilai estetika sebuah anyaman berkaitan erat dengan nilai ekonomisnya. Anyaman purun yang memiliki motif yang unik seperti susunan bangun datar beraturan sehingga membentuk pola tertentu yang dapat disesuaikan dengan keinginan. Desain motif yang beragam dan dapat disesuaikan dengan permintaan (by request) menjadi daya tarik pembeli. Keindahan sebuah anyaman purun terletak pada perpaduan warna yang menghasilkan 
berbagai motif anyaman seperti mata punai, tapak catur, saluang mudik, ramak cangkih, gigi haruan, anyam badiri dan anyam barabah. Bentuk anyaman menjadi unik ketika dapat membentuk huruf-huruf penyusun kata sesuai permintaan pembeli.

Pengrajin membayangkan motif mata punai sebagai wujud mata burung punai yang merupakan hewan dilindungi karena sudah mulai langka. Motif tapak catur dibayangkan sebagai papan catur dengan bentuk kotak berselang-seling dua warna. Motif saluang mudik dibayangkan sebagai bentuk ikan saluang yang hilir mudik berlawanan arah. Motif ramak cangkih dibayangkan sebagai kumpulan biji cengkeh yang beraturan. Motif gigi haruan dibayangkan sebagai bentuk gigi ikan haruan (ikan gabus). Motif anyam badiri dan anyam barabah dibayangkan sebagai anyaman sejajar vertikal dan anyaman sejajar horisontal. Adapun motif khusus lainnya dibuat sesuai permintaan pembeli, misalkan nama pemiliknya, nama kota, atau nama instansi.

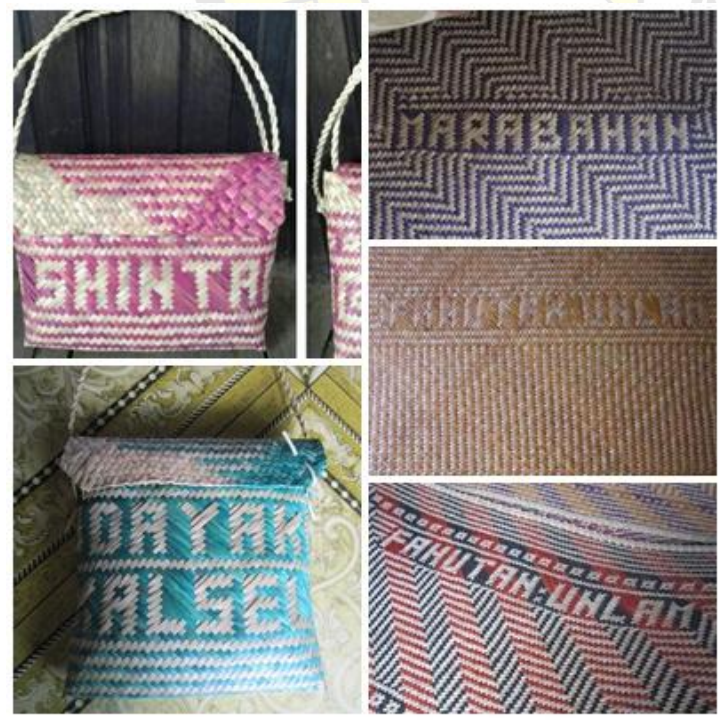

Gambar 6. Hasil Anyaman Purun

Selain itu, kebutuhan masyarakat akan barang-barang yang dihasilkan seperti topi, tikar, bakul, kipas, dan lainnya menjadi peluang bagi pengrajin. Anyaman purun dipasarkan baik lokal, nasional, bahkan internasional. Di antaranya dikirim ke Martapura, Banjarbaru, Kalimantan Timur, Kalimantan Tengah, Bali, Surabaya, dan Yogyakarta. Anyaman purun juga diimpor ke berbagai negara, seperti Taiwan dan Jepang. Berdasarkan pengumpulan data diperoleh informasi bahwa omset penjualan anyaman purun berkisar antara Rp25.000.000,00 sampai Rp30.000.000,00 dengan keuntungan bersih sekitar Rp5.000.000,00. Informasi ini mengindikasikan bahwa kerajinan anyaman bernilai ekonomis cukup tinggi.

\section{Simpulan}

\section{Simpulan dan Saran}

Motif pada anyaman purun memiliki bentuk geometri, yaitu mata punai dan tapak catur berupa bangun datar persegi, motif saluang mudik berupa bangun jajargenjang, ramak cangkih berupa bangun persegi panjang, gigi haruan berupa bangun segitiga samakaki dan sama sisi, serta anyam badiri dan barabah berupa susunan garis-garis sejajar (vertikal dan horisontal).

Anyaman purun memiliki nilai estetika (keindahan) yang berdampak pada munculnya nilai ekonomis. Nilai keindahan anyaman purun terletak pada kombinasi warna yang membentuk berbagai motif seperti mata punai, tapak catur, saluang mudik, ramak cangkih, gigi haruan, anyam badiri dan anyam barabah. Tingginya kebutuhan masyarakat akan barang-barang yang dihasilkan menjadikan anyaman purun bernilai ekonomis tinggi.

\section{Saran}

Adapun saran dalam penelitian ini adalah guru diharapkan dapat memanfaatkan kerajinan khas daerah 
setempat sebagai media pembelajaran matematika sehingga peserta didik lebih mengenal kearifan budaya lokalnya.

\section{Daftar Pustaka}

Ascher, M. 1991. Ethnomathematics: A Multicultural View of Mathematical Ideas. Pacific Grove: Brooks/Cole.

Ayatrohaedi. 1986. Kepribadian Budaya Bangsa (Local Genius). Jakarta: Pustaka Jaya.

D'Ambrosio U. 1997. Ethnomathematics and its Place in the History and Pedagogy of Mathematics. In A. Powell \& M. Frankenstein (eds.),Ethnomathematics,

Challenging Eurocentrism in Mathematics Education. Albany: State University of New York Press.

Dina, dkk. 2015. Materi Penyuluhan Pengabdian Kepada Masyarakat. Banjarmasin: Universitas Lambung Mangkurat.

Fraenkel, J. R., Wallen, N. E., \& Hyun H.

H. 2012. How to Design and
Evaluate Research in Education (8 ${ }^{\text {th }}$ Edition). New York: McGraw-Hill.

Glorin, G. (1980): Connecting Mathematics Practices In and Out of Schools. Journal of Ethnomathematics Canada, 3(2).

Harris, Marvin. 1999. Theories of Culture in Postmodern Times. New York: Altamira Press.

Koentjaraningrat. 1974. Pengantar Antropologi. Jakarta: Aksara Baru. Koentjaraningrat. 1981. Pengantar Antropologi. Jakarta: Rineka Cipta. Rahyono, F.X. 2009. Kearifan Budaya dalam Kata. Jakarta: Wedatama Widyasastra.

Suratman, Munir, \& Salamah. 2013. Ilmu Sosial \& Budaya Dasar. Malang: Intimedia. 